\title{
ACESSO À JURISDIÇÃO E O MANDADO DE SEGURANÇA COLETIVO COMO MEIO DE GARANTIR A PREVENÇÃO DO MEIO AMBIENTE DE TRABALHO EQUILIBRADO EM FRIGORÍFICOS ${ }^{1}$
}

\author{
Magno Federici Gomes* \\ Mariana Basílio Schuster de Souza ${ }^{* *}$
}

\begin{abstract}
RESUMO: A atividade frigorífica é um dos setores industriais que apresentam um meio ambiente de trabalho potencialmente lesivo aos empregados. Questiona-se se seria possível utilizar o mandado de segurança coletivo como meio de garantir a prevenção do meio ambiente de trabalho equilibrado em frigoríficos, tendo como como autoridade coatora o Ministro do Trabalho e Emprego. O objetivo é analisar o acesso à jurisdição para os trabalhadores do setor. Foi utilizada metodologia dedutiva, no tocante à pesquisa bibliográfica. A título de conclusões, a referida garantia constitucional coletiva pode ser utilizada para garantir um meio ambiente de trabalho equilibrado em frigoríficos.
\end{abstract}

Palavras-chave: Mandado de segurança coletivo; Direitos coletivos; Meio ambiente de trabalho; Frigoríficos.

\section{ACCESS TO JURISDICTION AND THE COLLECTIVE WRIT OF MANDAMUS TO ENSURE THE WORK ENVIRONMENT PREVENTION BALANCED IN SLAUGHTERHOUSES}

\begin{abstract}
The cooling activity is one of the industries that have a potentially harmful working environment for employees. Wonders whether it would be possible to use the collective writ of mandamus as a means to ensure prevention through balanced work environment in slaughterhouses, with the constraining authority as the Minister of Labor and Employment. The objective is to analyze access to jurisdiction for workers in the sector. This paper used deductive methodology, in relation to literature analysis. By way of conclusion, the collective writ of mandamus may be used to ensure a means balanced work environment in slaughterhouses.
\end{abstract}

Keywords: Collective writ of mandamus; Collective rights; Working environmental; Fridge.

\footnotetext{
${ }^{1}$ Trabalho financiado pelo Projeto FAPEMIG no 5236-15, resultante dos Grupos de Pesquisas (CNPQ): Regulação Ambiental da Atividade Econômica Sustentável (REGA), NEGESP, Metamorfose Jurídica e CEDIS (FCT-PT).

* Pós-doutor em Direito Público e Educação pela Universidade Nova de Lisboa-Portugal. Pós-doutor em Direito Civil e Processual Civil, Doutor em Direito e Mestre em Direito Processual, pela Universidad de Deusto-Espanha. Mestre em Educação pela PUC Minas. Professor do Mestrado Acadêmico em Direito Ambiental e Desenvolvimento Sustentável na Escola Superior Dom Helder Câmara. Professor Adjunto da PUC Minas e Professor Titular licenciado da Faculdade de Direito Arnaldo Janssen. Advogado Sócio do Escritório Moraes \& Federici Advocacia Associada. Líder do Grupo de Pesquisa: Regulação Ambiental da Atividade Econômica Sustentável (REGA)/CNPQ-BRA e integrante dos grupos: Centro de Investigação \& Desenvolvimento sobre Direito e Sociedade (CEDIS)/FCT-PT, Núcleo de Estudos sobre Gestão de Políticas Públicas (NEGESP)/CNPQBRA e Metamorfose Jurídica/CNPQ-BRA. ORCID: <http://orcid.org/0000-0002-4711-5310>. Currículo Lattes: $<$ http://lattes.cnpq.br/1638327245727283>. Endereço eletrônico: federici@pucminas.br

** Mestranda no Mestrado Acadêmico em Direito Ambiental e Desenvolvimento Sustentável na Escola Superior Dom Helder Câmara. Especialista em Direito Empresarial pela Universidade Estadual do Paraná. Advogada. Currículo Lattes: <http://lattes.cnpq.br/4566800674881863>. Endereço eletrônico: adv_marianabs@hotmail.com
} 


\section{INTRODUÇÃO}

A Constituição da República de 1988 (CR/1988) trouxe, em seu art. 225, o meio ambiente como garantia fundamental a todo o ser humano e apresentou ainda uma exigência, isto é, o meio ambiente ecologicamente equilibrado.

Meio ambiente pode ser entendido como "o conjunto de condições, leis, influências e interações de ordem física, química e biológica, que permite, abriga e rege a vida em todas as suas formas”, conforme conceituação trazida pelo art. 3, inciso I, da Lei ${ }^{0}$ 6.938/1981, que instituiu a Política Nacional do Meio Ambiente (PNMA).

Dentre os vários espécies do gênero meio ambiente, tem-se o meio ambiente de trabalho, que de modo simplificado é considerado aquele onde o empregado desenvolve as suas atividades laborais. O meio ambiente equilibrado e saudável também é garantia constitucional, abarcada no rol do art. $7^{\circ}$ e também no art. 196, ambos da CR/1988.

O empregador é o responsável por criar e manter um meio ambiente laboral sadio aos seus empregados, devendo tomar todas as medidas para prevenir, diminuir, neutralizar ou extinguir possíveis situações ou condições que apresentem qualquer tipo de risco à saúde e segurança do trabalhador.

O setor frigorífico é um dos campos industriais em que a atividade desempenhada pelo empregado pode ser considerada de alto potencial lesivo à saúde, dadas as condições de trabalho a que o empregado está exposto, como agentes químicos, físicos e biológicos. É um ramo de atividade industrial que tem elevado índices de acidente de trabalho, em razão do manuseio de refiladeiras, carga viva e manuseio de carcaça animal.

O mandado de segurança foi evoluindo ao longo do tempo, inicialmente utilizado para tutelar direitos que não eram passíveis de serem amparados pelo habeas corpus. Hoje é garantia constitucional e pode ser individual ou coletiva. O mandado de segurança coletivo é o instrumento processual possível para garantir o cumprimento de direitos coletivos e/ou individuais homogêneos, quando eles forem impedidos de ser exercidos por ato decorrente de ilegalidade ou abuso de poder cometido por autoridade pública ou agente de pessoa jurídica, no exercício de atribuições do Poder Público.

Ao refletir acerca desses pressupostos, questiona-se se seria possível utilizar o mandado de segurança coletivo como meio de garantir a prevenção do meio ambiente de trabalho equilibrado em frigoríficos.

Por considerar o trabalho executado em frigoríficos uma atividade de risco e pela notória 
importância do meio ambiente de trabalho saudável, é imperioso buscar meios processuais para garantir o direito do empregado que labora nesse ramo industrial, sendo esse o objetivo desta pesquisa, pois será analisado o acesso à jurisdição para os trabalhadores do setor.

Este estudo realizar-se-á por meio do método dedutivo, no que concerne à pesquisa bibliográfica e análise doutrinária, com conclusões objetivas acerca do tema proposto.

Primeiramente serão abordados conceitos de meio ambiente de trabalho, conceitos e panorama geral e o meio ambiente de trabalho em frigoríficos. Após, serão apresentadas noções sobre mandado de segurança coletivo e o seu cabimento, abrangendo a legitimidade ativa e passiva, bem como a autoridade coatora. Por fim, as considerações finais.

\section{MEIO AMBIENTE DO TRABALHO}

O meio ambiente do trabalho é o espaço físico onde o trabalhador desenvolve suas atividades laborais, remuneradas ou não. Deve ser um ambiente sadio em todos os sentidos, a fim de garantir a integridade física e psíquica dos empregados.

\subsection{Conceito e panorama geral}

A Lei $n^{\circ}$ 6.938/1981, que estabelece a PNMA, define meio ambiente, no inciso I, do seu art. $3^{\circ}$, como “conjunto de condições, leis, influências e interações de ordem física, química e biológica, que permite, abriga e rege a vida em todas as suas formas” (BRASIL, 1981). É uma conceituação mais naturalista.

O meio ambiente de trabalho é o conjunto de fatores que compõem o local de trabalho do empregado e deve ser seguro, na medida em que seus riscos devem ser reduzidos por meio de normas de saúde, higiene e segurança, conforme inciso XXII, do art. $7^{\circ}$, da CR/1988. Essa responsabilidade de garantir um meio ambiente de trabalho saudável é do empregador.

Para Nascimento (2009, p. 64-65), o meio ambiente de trabalhado é caracterizado por um conjunto de fatores que englobam a atividade exercida, abrangendo algumas garantias constitucionais trazidas na redação do art. $7^{\circ}$ da CR/1988.

Nesse contexto, entende-se que todos esses fatores, quando em harmonia com a legislação trabalhista, irão proporcionar ao empregado um ambiente sadio e agradável para desenvolver o trabalho. 
Com a CR/1988, o meio ambiente ganhou status de direito fundamental ao preconizar em seu art. 225 que "todos tem direito ao meio ambiente ecologicamente equilibrado, bem de uso comum do povo e essencial à sadia qualidade de vida, impondo ao Poder Público o dever de defendê-lo e preservá-lo para as presentes e futuras gerações” (BRASIL, 1988).

Ainda, o art. 196 da CR/1988 estabelece que "a saúde é direito de todos e dever do Estado, garantindo mediante políticas sociais e econômicas que vise à redução do risco de doença e outros agravos ao acesso universal e igualitário às ações e serviços para sua promoção, proteção e recuperação” (BRASIL, 1988). Nesse sentido, Melo esclarece que:

O meio ambiente do trabalho adequado e seguro é um direito fundamental do cidadão trabalhador (lato sensu). Não é mero direito trabalhista vinculado ao contrato de trabalho, pois a proteção daquele é distinta da assegurada ao meio ambiente do trabalho, porquanto essa última busca salvaguardar a saúde e a segurança do trabalhador no ambiente em que desenvolve as suas atividades (MELO, 2008, p. 68).

Como visto, o meio ambiente de trabalho está enquadrado no meio ambiente geral, por força do art. 200, inciso VIII, da CR/1988, logo, entende-se que é impossível obter qualidade de vida sem usufruir de qualidade de trabalho ${ }^{2}$, e na mesma medida, impossível atingir um meio equilibrado e sustentável sem observar o meio ambiente de trabalho (OLIVEIRA apud PADILHA, 2002, p. 32).

A nível internacional, destaca-se a Convenção 155 da Organização Internacional do Trabalho $(\mathrm{OIT})^{3}$, que foi aprovada pelo Brasil por meio do Decreto Legislativo $n^{\circ}$ 2/1992, e trata do meio ambiente de trabalho e saúde do trabalho, trazendo na redação das alíneas “c” e “e” do seu art. $3^{\circ}$ o conceito de local de trabalho e saúde, respectivamente, sendo local de trabalho aquele que "abrange todos os lugares onde os trabalhadores devem permanecer ou onde têm que comparecer, e que estejam sob o controle, direto ou indireto, do empregador” (BRASIL, 1992); e saúde com relação ao trabalho termo que “abrange não só a ausência de

\footnotetext{
${ }^{2}$ Para aprofundamento na dimensão jurídico política do desenvolvimento sustentável e no direito à renda oriunda do trabalho digno, como forma de se assegurar os direitos fundamentais intergeracionais, ver: GOMES, FERREIRA, 2017, p. 103-104.

${ }^{3}$ É uma agência da Organização das Nações Unidas criada em 1919, que tem como missão promover oportunidades para que homens e mulheres possam ter acesso a um trabalho decente e produtivo, em condições de liberdade, equidade, segurança e dignidade.
} 
afecções ou de doenças, mas também os elementos físicos e mentais que afetam a saúde e estão diretamente relacionados com a segurança e a higiene no trabalho” (BRASIL, 1992).

A Consolidação das Leis do Trabalho (CLT) contempla os temas de segurança e Medicina do Trabalho em seus arts. 154 a 223, na seguinte sequência: nos arts. 155 a 159, trata das normas básicas de segurança e os órgãos competentes para zelar pela Segurança e Medicina do Trabalho; no art. 160 refere-se à inspeção prévia, embargo ou interdição de estabelecimento; nos arts. 162 a 165 aborda os órgãos nas empresas; nos arts. 166 e 167 versa sobre os equipamentos de proteção individual; nos arts. 168 e 169, faz alusão às medidas preventivas; nos arts. 170 a 174 cuida das edificações; no art. 175 aborda a iluminação; nos arts. 176 a 178 sobre o conforto térmico; os arts. 179 e 189 refere-se às instalações elétricas; nos arts. 182 e 183 tem-se o manuseio e armazenagem; nos arts. 184 a 186, máquinas e equipamentos; nos arts. 187 e 188 dispõe sobre caldeiras, fornos e recipientes sob pressão; os arts. 189 a 197 tratam das atividades insalubridades ou perigosas e formas de neutralização do risco; nos artigos 198 e 199 da prevenção da fadiga; e no art. 200 tem-se a competência do Ministério do Trabalho e Emprego para editar normas regulamentares - NRs. (BRASIL, 1943). Destaca-se o art. 157 da CLT que trata da responsabilidade do empregador:

[...] I - cumprir e fazer cumprir as normas de segurança e medicina do trabalho;

II - instruir os empregados, através de ordens de serviço, quanto às precauções a tomar no sentido de evitar acidentes do trabalho ou doenças ocupacionais;

III - adotar as medidas que lhes sejam determinadas pelo órgão regional competente;

IV - facilitar o exercício da fiscalização pela autoridade competente (BRASIL, 1943).

Já o art. 158 da CLT elenca as responsabilidades do empregado:

[...] I - observar as normas de segurança e medicina do trabalho, inclusive as instruções de que trata o item II do artigo anterior;

Il - colaborar com a empresa na aplicação dos dispositivos deste 
Capítulo.

Parágrafo único - Constitui ato faltoso do empregado a recusa injustificada:

a) à observância das instruções expedidas pelo empregador na forma do item II do artigo anterior;

b) ao uso dos equipamentos de proteção individual fornecidos pela empresa (BRASIL, 1943).

Importante mencionar também que, conforme art. 200 da CLT, o Ministério do Trabalho ficou responsável por editar NRs para disciplinar assuntos específicos relacionados ao meio ambiente de trabalho. Essas normas, de acordo com o item 1 da NR 1 "são de observância obrigatória pelas empresas privadas e públicas e pelos órgãos públicos da administração direta e indireta, bem como pelos órgãos dos Poderes Legislativo e Judiciário, que possuam empregados regidos pela Consolidação das Leis do Trabalho - CLT” (BRASIL, 1978). Atualmente já foram editadas trinta e seis NRs.

Se pode compreender que a responsabilidade pelo meio ambiente de trabalho equilibrado além de ser dever do empregador e empregado, também pode ser atribuída ao Poder Público, na medida em que, por meio de seus órgãos competentes, deve estabelecer normas para regular e configurar os padrões de saúde a serem seguidos, bem como as condições de insalubridade e periculosidade que serão consideradas aceitáveis de serem suportados pelo trabalhador, e ainda diretrizes para o empregador reduzir ou eliminar eventuais danos.

Além da edição dessas normas, uma das funções do Poder Público é a de fiscalizar e exigir a aplicação dessas normativas.

\subsection{Meio ambiente do trabalho em frigoríficos}

A indústria frigorífica constitui unidade operacional completa, compreendida desde o controle da matéria prima, recepção dos animais (aves, suínos, bovinos), o processamento, a estocagem e expedição do produto, tendo como eixo central uma linha contínua de desmontagem do animal (COSTELLA; MASSON, 2012, p. 2; e VASCONCELLOS; PIGNATTI; PIGNATI, 2009, p. 666-667).

Para fazer do meio ambiente de trabalho em frigorífico um ambiente menos nocivo ao trabalhador, e visando alcançar um meio ambiente de trabalho equilibrado, o Ministério do 
Trabalho e Emprego editou em abril de 2013 a NR 36, que trata da segurança e saúde no trabalho em empresas de abate e processamento de carnes e derivados.

A NR 36 é composta por 16 itens que tratam: no item 36.1 dos objetivos; no item 36.2 sobre mobiliário e postos de trabalho; no item 36.3 sobre estrados, passarelas e plataformas; no item 36.4, manuseio de produtos; no item 36.5 sobre levantamento e transporte de produtos e cargas; no item 36.6 da recepção e descarga de animais; no item 36.7 das máquinas; no item 36.8 sobre equipamentos e ferramentas; no item 36.9 sobre as condições ambientais de trabalho; no item 36.10 dos equipamentos de proteção individual (EPI) e vestimentas; no item 36.11 sobre o gerenciamento dos riscos; no item 36.12 os programas de prevenção dos riscos ambientais e de controle médico de saúde ocupacional; no item 36.13 sobre a organização temporal do trabalho, no item 36.14 sobre a organização das atividades; no item 36.15 a análise ergonômica do trabalho; no item 36.16 as informações e treinamentos em segurança e saúde no trabalho. A NR 36 traz ainda um anexo contendo o glossário e os prazos de implementação. Constante no item 36.1.1, essa NR foi editada com o objetivo de:

[...] estabelecer os requisitos mínimos para a avaliação, controle e monitoramento dos riscos existentes nas atividades desenvolvidas na indústria de abate e processamento de carnes e derivados destinados ao consumo humano, de forma a garantir permanentemente a segurança, a saúde e a qualidade de vida no trabalho, sem prejuízo da observância do disposto nas demais Normas Regulamentadoras - NR do Ministério do Trabalho e Emprego (BRASIL, 2013).

Notório que para o funcionamento do trabalho em indústrias frigoríficas, indispensável a utilização de câmaras frias para manipulação e armazenamento do produto. Ocorre que o frio é um agente físico considerado ameaçador para a saúde do trabalhador, e por esse motivo, como exemplo para reduzir o risco, é obrigatório que o empregador forneça ao empregado vestimentas adequadas com isolante térmico, conforme disposto no art. 177 da CLT, bem como no item 36.10.2 da NR $36^{4}$.

\footnotetext{
${ }^{4}$ 36.10.2 O empregador deve fornecer vestimentas de trabalho de maneira que: a) os trabalhadores possam dispor de mais de uma peça de vestimenta, para utilizar de maneira sobreposta, a seu critério, e em função da atividade e da temperatura do local, atendendo às características higiênico-sanitárias legais e ao conforto térmico;
} 
Mas não é somente esse risco ao qual o trabalhador nesse ramo industrial está exposto. De acordo com Costella e Masson:

No segmento frigorífico o funcionário está exposto, de forma mais significativa, aos riscos de acidentes (facas, discos de cortes de equipamentos, partes móveis de máquinas), físicos (ruídos) e ergonômicos (posturas desconfortáveis, movimentos repetitivos), sendo que, todas as medidas de segurança adotadas pela empresa, tem a finalidade de proteger as pessoas de forma a eliminar, isolar ou sinalizar os riscos existentes em cada atividade ou posto de trabalho que demande de um fator humano. Assim, a análise dos riscos no meio ambiente de trabalho é um assunto que demanda participação de todos os integrantes da empresa (COSTELLA; MASSON, 2012, p. 02).

Todos esses riscos e maneiras de amenizá-los estão previstos na NR 36, que deve ser seguido à risca pelas empresas, sob pena de multa a ser aplicada pelo Ministério do Trabalho e Emprego, quando houver fiscalização.

Verifica-se no texto da NR 36 a preocupação para abranger todos os pontos necessários para manter a saúde e segurança do trabalhador, quando apresentados questões específicas como “os equipamentos e ferramentas disponibilizados devem favorecer a adoção de posturas e movimentos adequados, facilidade de uso e conforto, de maneira a não obrigar o trabalhador ao uso excessivo de força, pressão, preensão, flexão, extensão ou torção dos segmentos corporais” (BRASIL, 2013, item 36.8.1).

A NR 36 vincula à observância dos níveis de ruído, qualidade do ar, níveis de exposição a agentes químicos e agentes biológicos. Obriga o empregador a ter um Plano de Resposta a Emergências em caso de vazamento de amônia no local de trabalho. Determina a adoção de medidas para garantir o conforto térmico, como controle da temperatura e umidade do ar, fornecimento de EPI em conformidade com o local e temperatura de trabalho do empregado. Estabelece os critérios para gerenciar os riscos possíveis no meio ambiente de trabalho, entre outras providências.

b) as extremidades sejam compatíveis com a atividade e o local de trabalho;

c) sejam substituídas quando necessário, a fim de evitar o comprometimento de sua eficácia.

36.10.2.1 As vestimentas devem ser trocadas diariamente, sendo sua higienização responsabilidade do empregador (BRASIL, 2013). 
O art. 253, caput, da CLT, garante ao trabalhador o intervalo para recuperação térmica:

para os empregados que trabalham no interior das câmaras frigoríficas e para os que movimentam mercadorias do ambiente quente ou normal para o frio ou vice-versa, depois de uma hora e quarenta minutos de trabalho contínuo será assegurado um período de vinte minutos de repouso, computado esse intervalo com o de trabalho efetivo (BRASIL, 1943).

A atividade desenvolvida em frigoríficos pode ser considerada de risco, e é fato que é uma atividade insalubre, devendo ser respeitados os usos de EPIs bem como o intervalo de descanso especificado no art. 253 da CLT.

Com tantos quesitos apontados nas NRs, mesmo adotando todas as medidas necessárias para diminuir, neutralizar ou extinguir os riscos no meio ambiente de trabalho frigorífico, presume-se que o labor nesse setor não é saudável para o empregado. Há muitos acidentes de trabalho e doenças ocupacionais.

A exemplo, entre o ano de 2002 a 2005 foi feita uma pesquisa no Estado do Mato Grosso, onde constatou-se que a faca é o instrumento responsável por “43,3\% dos acidentes de trabalho registrados por meio das Comunicações de Acidentes de Trabalho” (CAT). Outras causas apontadas foram "peças de carne (6,2\%), água (4,2\%), embalagens e caixas (2,4\%), máquinas (2,2\%) e animal vivo (2,0\%), sendo que os dedos, mão (exceto punho e dedos), antebraço e braço foram as partes do corpo mais atingidas” nos acidentes analisados, totalizando 59,7\% das ocorrências. Em 95,8\% dos casos houve afastamento do funcionário (VASCONCELLOS; PIGNATTI; PIGNATI, 2009, p. 668-669). Ainda, de acordo com Vasconcellos, Pignatti e Pignati:

Considerando a complexidade das exigências implícitas nas ocupações descritas, o próprio processo de produção, os trabalhos com produtos perecíveis que faz com que os trabalhadores tenham que trabalhar muito rapidamente, constituindo uma das características que contribui para as condições de trabalho nas unidades frigoríficas, pode-se supor que as causas imediatas desses acidentes estejam associadas a outras situações 
que não aparecem nas estatísticas, como, por exemplo, aspectos da organização do trabalho e/ou do gerenciamento da empresa (VASCONCELLOS, PIGNATTI E PIGNATI, 2009, p. 669).

Além dos acidentes de trabalho, as doenças laborais vêm ganhando destaque no setor frigorífico. Essas doenças "têm relação com a organização do trabalho e a exigência de uma produção que ocorre que forma sequencial, fragmentada, sujeita à cadência impostas pelas máquinas” (VASCONCELLOS; PIGNATTI; PIGNATI, 2009, p. 669).

Conforme as Diretrizes para Programas de Gerenciamento Ergonômico para empresas de Abate e Processamento de Carnes, editada antes da NR 36, as empresas deveriam adotar os seguintes critérios para reduzir as doenças ocupacionais nos frigoríficos:

a) alteração na velocidade do processo produtivo; b) redução do números total de repetições por trabalhador, por meio da redução dos níveis da produção, bem assim a limitação de horas extras; c) pausas de recuperação de fadiga; d) aumento do número de empregados designados para realizar as tarefas mais críticas, especialmente em relação ao levantamento de objetos pesados; e) rodízio de tarefas; f) número suficiente de empregados para produção e para cobrir absenteísmo (SARDA; RUIZ; KIRTSCHIG, 2009, p. 62).

Caso sejam descumpridas tais recomendações, passa-se a análise do cabimento do mandado de segurança coletivo.

\section{MANDADO DE SEGURANÇA COLETIVO}

Com o passar dos anos, surgiram os direitos de terceira geração ou direitos de terceira dimensão, que se caracterizam os direitos coletivos dos cidadãos. Essa coletividade se refere a um grupo, como por exemplo, de determinada categoria laboral. Para tutelar a defesa desses direitos surgiu a necessidade de criação de medidas processuais adequadas, sendo um deles, o mandado de segurança coletivo, objeto do presente estudo.

\subsection{Breves noções históricas}


De acordo com Meirelles, mandado de segurança é:

o meio constitucional posto à disposição de toda pessoa física ou jurídica, órgão com capacidade processual, ou universalidade reconhecida por lei, para a proteção de direito individual líquido e certo, não amparado por “habeas corpus”, lesado ou ameaçado de lesão, por ato de autoridade, seja de que categoria for e sejam quais forem as funções que exerça (MEIRELLES, 2015, p. 11).

O mandado de segurança apresentado no ordenamento jurídico brasileiro, quando posto em comparação a outros institutos, se assemelha com o writ americano, o mandamus inglês e o judicio de amparo, do direito mexicano. Sobre esse último, explica Fiorillo:

[...] judicio de amparo, que é um remédio constitucional contra as arbitrariedades do Estado, mas cujo campo de incidência é superior ao do nosso mandado de segurança. Em linhas gerais, o amparo só é possível por iniciativa da parte, sendo essencial a existência de dano ou prejuízo pessoal, e dificilmente contra atos administrativos ou jurisdicionais (FIORILLO, 2012, p. 257).

No Brasil, o mandado de segurança surgiu como um desdobramento do habeas corpus, sendo utilizado para tutelar a proteção de assuntos diversos do Direito penal.

Na Constituição de 1934, foi a primeira vez que um texto constitucional trouxe previsão expressa sobre mandado segurança. Em 1937, durante a ditadura militar, na era Vargas (19371945), o mandado de segurança foi retirado do texto constitucional, sendo mantida sua vigência no plano infraconstitucional.

Em 1946, após a queda de Vargas, o mandado de segurança foi restaurado juntamente com outras garantias individuais suprimidas durante a ditadura.

No ano de 1951 foi promulgada a Lei $n^{\circ} 1.533 / 1951$, a qual regulamentou fora do plano constitucional o mandado de segurança. Foi alterada posteriormente pelas Leis $n^{\circ}$ 4.166/1962, $4.248 / 1964$ e 5.021/1966. 
Na Constituição de 1967, foi inserida a expressão “proteção a direito individual”, tendo sido modificado pela Constituição de 1969 que retirou do texto a expressão “individual”, o que permitiu a tutela de direitos que ultrapassavam o indivíduo.

Somente com a CR/1988 admitiu-se expressamente o mandado de segurança coletivo e os legitimados para a sua propositura, previsto no art. 5 , inciso LXX, podendo agora ser utilizado esse mecanismo processual em várias situações.

Por fim, em 2009 foi promulgada a Lei 12.016/2009 que trouxe algumas mudanças em relação à Lei $n^{\circ}$ 1.533/1951, revogando esta.

\subsection{Mandado de segurança coletivo e seu cabimento}

De acordo com Fiorillo (2012, p. 262) “o mandado de segurança coletivo nada mais é do que uma forma de se impetrar o mandado de segurança tradicional”, sendo o termo “coletivo” referente a regra de legitimidade ativa do writ. Nesse mesmo entendimento, o doutrinador Silva explica que:

O conceito de mandado de segurança coletivo assenta-se em dois elementos: um institucional, caracterizado pela atribuição da legitimação processual a instituições associativas para a defesa dos interesses de seus membros ou associados; outro objetivo, consubstanciado no uso do remédio para a defesa de interesses coletivos. Logo, as associações que tenham entre as suas finalidades institucionais a proteção do meio ambiente também estão investidas de legitimação para impetrar mandado de segurança coletivo com tal objeto (SILVA, 2004, p. 322).

O mandado de segurança coletivo é medida utilizada para tutelar direito líquido e certo, conforme caput do art. 21 da Lei no 12.016/2009. Para Grinover:

O direito líquido e certo (expressão no sentido exclusivamente processual) a ser protegido pela via de segurança coletiva desdobra-se em três categorias de interesses: os difusos, os coletivos e os individuais homogêneos... quer os legitimados pela alínea $a$, quer os legitimados 
pela alínea $b$ podem agir em juízo em via de mandado de segurança coletivo, para a proteção de interesses difusos que transcendem toda a categoria; de interesses coletivos de parte ela; de direitos individuais, que por sua homogeneidade devem ter tratamento coletivo (GRINOVER, 1990, p. 05).

Antes da Lei $n^{\circ}$ 12.016/2009 era entendido que o mandado de segurança coletivo poderia ser usado para tutelar interesses relacionados à qualidade de vida, os conhecidos direitos difusos, dentre os quais, o meio ambiente é o exemplo mais expressivo. Theodoro Júnior explica que esse entendimento encontra resistência doutrinária:

[...] a controvérsia foi enfrentada pela Lei 12.016/2009, que, ao regular o regime do mandado de segurança coletivo, prévio que os direitos por ele protegidos são os coletivos e os individuais homogêneos (art. 21, parágrafo único). Ficaram, portanto, fora de seu alcance os direitos difusos como o que se deu guarida à exegese restritiva. Os direitos difusos, quando violados ou ameaçados, haverão de ser tutelados pela ação civil pública e não pelo mandado de segurança coletivo (THEODORO JÚNIOR 2009, p. 32).

Carvalho Filho, que partilha do mesmo entendimento, explica seus motivos:

A uma, porque o texto constitucional (e também o da lei) não alude aos interesses difusos; a duas, porque tal proteção é incompatível com o mandado de segurança coletivo, sabido que os referidos interesses pertencem a destinatários indeterminados (e não determináveis, como são os interesses coletivos), o que, a nosso ver, não constitui objeto da ação; e a três, porque tais interesses já são tutelados por outros instrumentos com expressa previsão legal (CARVALHO FILHO, 2011, p. 154).

Esses conceitos de direitos difusos, coletivos e individuais homogêneos são os trazidos 
pelo art. 81 do Código de Defesa do Consumidor (CDC).

Em outras palavras, os direitos coletivos, são os que ultrapassam o aspecto individual para estender seus efeitos sobre um grupo ou categoria de pessoas, podendo ser considerada uma espécie de soma de direitos individuais e também, um direito próprio do grupo. Os titulares podem ser determinados e ligados entre si ou com a parte contrária, em razão de uma relação jurídica base. Já o direito individual homogêneo, possui origem comum e envolve várias pessoas determinas que estão ligadas entre si por uma relação fática, e buscam o mesmo objetivo (SCHIAVI, 2015, p. 1438).

O direito ao meio ambiente do trabalho equilibrado e sadio é garantia constitucional e infraconstitucional, e pode ser considerado um direito difuso, pois se trata de um direito constitucional fundamental, mas quando esse direito se refere especificamente ao trabalho em frigorífico, considera-se um direito coletivo, uma vez que diz respeito somente aos empregados que trabalham nesse setor industrial.

Desta forma, reconhece ser o meio ambiente de trabalho em frigorífico bem jurídico coletivo, líquido e certo, passível de ser tutelado por mandado de segurança coletivo.

\subsection{Legitimidade ativa e passiva}

O caput do art. 21 da Lei no 12.016/2009 dispõe:

Art. 21. O mandado de segurança coletivo pode ser impetrado por partido político com representação no Congresso Nacional, na defesa de seus interesses legítimos relativos a seus integrantes ou à finalidade partidária, ou por organização sindical, entidade de classe ou associação legalmente constituída e em funcionamento há, pelo menos, 1 (um) ano, em defesa de direitos líquidos e certos da totalidade, ou de parte, de seus membros ou associados, na foram de seus estatutos e desde que pertinentes às suas finalidades, dispensada, para tanto, autorização especial (BRASIL, 2009).

Com relação à legitimidade dos partidos políticos, o Supremo Tribunal Federal (STF) tem entendido, de acordo com Mendes e Branco (2014, p. 442), “que o mandado de segurança coletivo poderá ser utilizado apenas para a defesa de direitos de seus filiados, observada a 
correlação com as finalidades institucionais e objetivos programáticos da agremiação”.

Antes da Lei $\mathrm{n}^{\circ}$ 12.016/2009, a doutrina entendia que partido político possuía uma legitimidade mais ampla para a impetração do mandado de segurança coletivo, não era limitado apenas à defesa dos direitos e interesses de seus filiados (GAJARDONI; FONSECA, 2012, p. 08). Ou seja, com o advento da nova lei de Mandado de Segurança, os partidos políticos tiveram sua legitimidade restringida:

Com a Lei 12.016/09, lamentavelmente, consolida-se legalmente este entendimento jurisprudencial restritivo. Mais do que isto; extirpa-se a possibilidade de os direitos fundamentais serem tutelados genericamente pelos partidos políticos, uma vez que o art. 21, caput, da lei é claro no sentido de que a legitimação é limitada à defesa de seus interesses legítimos relativos a seus integrantes (defesa de direitos líquidos e certos da totalidade, ou de parte, dos seus filiados, no que pertinentes às suas finalidades: art. $1^{\circ}$ da LOPP - garantias fundamentais) ou à finalidade partidária (regime democrático e sistema representativo). Portanto, a impetração do mandado de segurança coletivo por partido político, no regime da nova LMS, ocorre: a) na defesa dos interesses legítimos relativos a seus integrantes (garantias fundamentais dos filiados); e b) nos assuntos relacionados à finalidade partidária (GAJARDONI; FONSECA, 2012, p. 08).

Existe uma corrente que entende que a legitimidade dos partidos políticos é mais ampla, a exemplo, Grinover, citada por Barbosa e Costa:

Por isso, o partido político está legitimado a agir para a defesa de todo e qualquer direito, seja ele de natureza eleitoral ou não. No primeiro caso o partido estará defendendo os seus próprios interesses institucionais, para os quais se constitui. Agirá, a nosso ver investido de legitimação ordinária. No segundo caso - quando, por exemplo, atuar para a defesa do meio ambiente, do consumidor, dos contribuintes -, será substituto processual, defendendo em nome próprio interesses 
alheios. Mas nenhuma outra restrição deve sofrer quanto ais interesses e direitos protegidos: além da tutela dos direitos coletivos e individuais homogêneos, que se titularizam nas pessoas filiadas ao partido, pode o partido buscar, pela via de segurança coletiva, aquela atinente a interesses difusos, que transcendam aos seus filiados (GRINOVER apud BARBOSA; COSTA, 2010, p. 35).

Outros legitimados para impetrar o mandado de segurança coletivo são as organizações sindicais, entidades de classe ou associações, que devem representar seus legitimados com a matéria defendida possuir pertinência temática. Gajardoni e Fonseca apresentam os seguintes conceitos:

Sindicato é órgão de representação das categorias profissionais (que tem natureza de associação, ainda que com prerrogativas especiais), competindo-lhe, nos termos da Carta Constitucional, a defesa dos interesses ou direitos coletivos ou individuais da categoria, inclusive nas questões administrativas ou judiciais (art. $8^{\circ}$, III, da CF)12. A sua constituição é feita da mesma forma que a da associação civil, mas com necessidade de posterior depósito de seus estatutos para registro no Ministério do Trabalho (art. 513 da CLT).

Já as entidades de classe ou associações são entes que, no seu âmbito, agregam pessoas com um propósito comum (profissionais ou não) e que, por isto mesmo, unem forças em prol de objetivos previamente eleitos nos estatutos sociais. Trata-se de um gênero, do qual os sindicatos são espécies (GAJARDONI; FONSECA, 2012, p. 09).

Conforme texto da Lei do Mandado de Segurança, bem como o da CR/1988, as entidades de classe ou associações devem estar constituídas há, pelo menos, um ano.

Tantos os sindicatos quanto entidades de classes e associações podem impetrar o mandamus coletivo para defender interesses de seus membros/associados, não havendo necessidade de tutelar somente temas previstos no estatuto, diferentemente dos partidos políticos.

O professor Nery Junior, citado por Fiorillo, esclarece acerca da legitimidade dos 
sindicatos:

Com o advento da Constituição Federal de 1988, os Sindicatos deixaram de ser tutelados pelo governo e têm hoje o perfil de associação civil. A estes foi dada legitimidade para a defesa, inclusive em juízo, dos direitos e interesses coletivos e individuais da categoria (art. $8^{\circ}$, III, CF/88), podendo, outrossim, impetrar Mandado de Segurança Coletivo (art. 5, LXX, b, da CF/88). A legitimidade extraordinária dos sindicatos, independentemente de serem consideradas como associação civil, é extraída diretamente da Constituição Federal, como se disse no início desse comentário (NERY JÚNIOR apud FIORILLO, 2012, p. 268).

Parcela da doutrina, bem como uma corrente jurisprudencial, afirmam que o Ministério Público seria parte legítima para propor mandado de segurança coletivo, embora ele não conste no rol do art. 21 da Lei $\mathrm{n}^{\circ}$ 12.016/2009, tampouco do art. 5º inciso LXX, $a$ e $b$, da CR/1988. Os que entendem dessa forma, utilizam o art. 129, inciso III, da CR/1988, reforçado pela súmula 643 do STF (LUKACHEWSKI JÚNIOR, 2012, p. 399).

Fiorillo é um dos defensores da não taxatividade do rol do art. 21, e sobre o Ministério Público, justifica:

Além disso, junte-se a isso, o fato de que, tratando-se de tutela de bens de valores ambientais, cuja natureza transcende a individualidade, não há como negar ao Ministério Público, por conta da sua própria função institucional, que a defesa dos direitos difusos, coletivos e individuais indisponíveis, a atuação da tutela processual de bens de valores ambientais, conforme se verifica no art. 127 da Constituição Federal (FIORILLO, 2012, p. 265).

Como objetivo deste estudo, busca-se avaliar o cabimento do mandando de segurança coletivo como forma de garantir o meio ambiente de trabalho equilibrado em frigoríficos.

Caso o meio ambiente do trabalho para os empregados da classe citada não esteja sadio 
e dentro das normas estabelecidas pela legislação e diretrizes do Ministério do Trabalho e Emprego, o sindicato dos empregados em estabelecimentos frigoríficos é plenamente legítimo para impetrar mandado de segurança coletivo, visando resguardar o direito de toda a classe trabalhadora a qual representa.

Será legitimado passivo a autoridade coatora que praticou o ato impugnado ou da qual emanou a ordem para a sua prática, conforme $\S 3^{\circ}$, do art. $6^{\circ}$ da Lei $n^{\circ} 12.016 / 2009$.

Em relação a esse item, o texto de lei é claro e taxativo, não havendo questionamentos.

Fiorillo esclarece sobre como essa taxatividade limita a utilização do mandado de segurança coletivo na tutela do meio ambiente:

Disso surge uma acentuada restrição à utilização do mandado de segurança na tutela do meio ambiente, porque o conceito de poluidor, que é trazido pela Lei $\mathrm{n}^{\circ}$ 6.938/81 e principalmente observado em face do que determina o art. 225, parágrafo $3^{\circ}$ da Constituição Federal, é muito mais amplo do que aquele que pode ser encontrado na norma constitucional, de modo que essa dissonância acaba por torná-lo um instrumento de diminuta operatividade quanto à defesa dos bens e valores ambientais (FIORILLO, 2012, p. 272).

Embora exista essa restrição com relação a sua eficácia, no problema apresentado neste artigo, parece ser perfeitamente cabível a utilização do mandado de segurança coletivo.

O empregador tem a obrigação de proporcionar um meio ambiente de trabalho equilibrado ao funcionário, e no ambiente frigorífico, que é uma atividade de risco, deve fazer cumprir as diretrizes apontadas na NR36.

Cabe ao Ministério do Trabalho e Emprego (MTE), exercendo seu poder de polícia, a fiscalização do cumprimento das normas referentes à segurança e medicina do trabalho.

Se o empregador não cumpre as normas referentes ao meio ambiente de trabalho, e o Ministério do Trabalho e Emprego não efetua as fiscalizações e deixa de cobrar do empregador o cumprimento da lei, tem-se uma omissão do órgão representante do Poder Público, cabendo ao sindicato da categoria, no interesse dos direitos de seus associados, impetrar mandado de segurança coletivo em face do MTE, visando a obrigação do representante do Poder Público exigir do empregador o cumprimento das leis, garantindo assim o meio ambiente ecologicamente equilibrado. Assim, "um dos desafios da jurisdição, enquanto tarefa estatal 
estratégica é contribuir para que a tutela do meio ambiente reencontre o seu adequado fundamento no dever fundamental de solidariedade, religando assim os seres humanos com a teia da vida" (BODNAR, 2009, p. 111).

No problema apresentado, a autoridade coatora será o responsável pela Delegacia Regional do Trabalho e Emprego, ou o agente subordinado a esse órgão que se omitiu em exigir e/ou fiscalizar o cumprimento da lei. Contudo, o impetrado será o Ministro do Trabalho, respeitada a hierarquia da instituição. Nesse caso, a competência constitucional para apreciar o mandado de segurança coletivo será do Superior Tribunal de Justiça, conforme art. 105, alínea $b$, da $\mathrm{CR} / 88$.

\section{CONSIDERAÇÕES FINAIS}

O meio ambiente de trabalho ecologicamente equilibrado e sadio é garantia constitucional por força dos arts. $7^{\circ}, 196$ e 225 da CR/1988 e deve ser garantido aos trabalhadores, sendo esse um dever do empregador.

A atividade frigorífica é um ramo do setor industrial com grande representatividade no país. É um trabalho que colocam os empregados em situações que representam efetivos riscos à saúde e segurança, pois, como visto, envolve o controle da matéria prima, recepção dos animais (aves, suínos e bovinos), o processamento, a estocagem e expedição do produto, tendo como eixo central uma linha contínua de desmontagem do animal. Tal atividade expõe o trabalhador constantemente a agentes nocivos físicos, químicos e biológicos.

Ao se partir dessa premissa, entende-se que atividade desenvolvida pelos frigoríficos é de risco, o que se embasa pelo anexo V do Decreto $n^{0}$ 3.048/1999, com a redação do Decreto $\mathrm{n}^{0} 6.957 / 2009$. Tais atos administrativos normativos estabelecem que a atividade desenvolvida em frigoríficos é nociva em grau 3, bem como a NR 04, traz em seu quadro 01 a atividade de abate e fabricação de produtos de carne como atividade de risco com grau 3, numa escala que vai de 0 a 4 , sendo o 4 o máximo.

Isso posto, o empregador deve adotar todas as medidas preventivas necessárias para reduzir, neutralizar e/ou minimizar os danos que podem ser causados aos empregados. Contudo, mesmo que o empregador tome todas as precauções a ele incumbidas (especificadas na CLT e nas NRs do MTE), o empregado pode vir a sofrer algum tipo de dano, em geral, ocasionado por acidente de trabalho. 
O mandado de segurança coletivo é remédio constitucional no qual são legitimados ativos para impetrá-lo o partido político com representação no Congresso Nacional, na defesa de seus interesses legítimos relativos a seus integrantes ou à finalidade partidária, ou por organização sindical, entidade de classe ou associação legalmente constituída e em funcionamento há, pelo menos, 01 (um) ano, em defesa de direitos líquidos e certos da totalidade, ou de parte, de seus membros ou associados.

Pela análise feita ao longo deste estudo, compreende-se que o mandando de segurança coletivo é medida processual perfeitamente cabível para tutelar o meio ambiente de trabalho, visando garantir o seu equilíbrio e salubridade para os trabalhadores de frigoríficos.

Por sua vez, o MTE, além de editar normas regulamentadoras sobre meio ambiente, segurança e medicina no trabalho, tem o dever de fiscalizar o cumprimento da legislação trabalhista, exercendo seu poder de polícia, bem como a faculdade de aplicar multas quando constatado o descumprimento de tais obrigações. Quando o órgão representante do Poder Público deixa de efetuar essa fiscalização, tem-se um ato atentatório ao meio ambiente de trabalho, por omissão, cabendo a impetração de mandado de segurança coletivo. A autoridade coatora será o responsável pela Delegacia Regional do Trabalho e Emprego, ou agente submetido a este órgão, e o impetrado será o Ministro do Trabalho, respeitando a hierarquia institucional.

Consideradas as peculiaridades relativas ao meio ambiente de trabalho em frigoríficos e que tal classe possui representatividade por meio do sindicato da categoria, entende-se que ele, por força da CR/88, é parte legítima para impetrar mandado de segurança coletivo, em face do órgão coator representante do Poder Público - no caso o Ministro de Estado do Trabalho e Emprego, quando ocorrer omissão do MTE no dever de fiscalizar o meio ambiente do trabalho em frigoríficos, visando exigir que o órgão competente obrigue ao empregador o cumprimento da legislação trabalhista, bem como para que previna eventuais danos aos trabalhadores.

\section{REFERÊNCIAS}

BARBOSA, Guilherme Barbosa Vieira; COSTA, Yvete Flávio da. A Lei 12.016/09 e seu reflexo jurídico nos mandados de segurança coletivos. Revista de Direito dos Monitores da Universidade Federal Fluminense, Rio de Janeiro, nº 7, p. 1-22, jan./abr. de 2010. Disponível em: <http://www.rdm.uff.br/index.php/rdm/article/view/131>. Acesso em: 31 mar. 2018. 
BODNAR, Zenildo. Os novos desafios da jurisdição para a sustentabilidade na atual sociedade de risco. Veredas do Direito, Belo Horizonte, v. 6, nº 12, p. 101-119, jul./dez. 2009. Disponível em: <http://www.domhelder.edu.br/revista/index.php/veredas/article/view/19>. Acesso em: 31 mar. 2018.

BRASIL. Constituição (1988). Constituição da República Federativa do Brasil. Brasília: Senado Federal, Centro Gráfico, 1988.

BRASIL. Decreto Legislativo n ${ }^{2}$, de 1994. Aprova o texto da Convenção sobre Diversidade Biológica; assinada durante a Conferência das Nações Unidas sobre Meio Ambiente e Desenvolvimento realizada na Cidade do Rio de Janeiro, no período de 5 a 14 de junho de 1992. Diário Oficial da União, Brasília, 04 fev. 1994. Disponível em: <http://www2.camara.leg.br/legin/fed/decleg/1994/decretolegislativo-2-3-fevereiro-1994358280-publicacaooriginal-1-pl.html>. Acesso em: 31 mar. 2018.

BRASIL. Decreto-Lei $n^{0}$ 5.452, de $1^{\circ}$ maio 1943. Aprova a consolidação das leis do trabalho. Diário Oficial da União, Brasília, 9 ago. 1943. Disponível em: <http://www.planalto.gov.br/ccivil_03/decreto-lei/Del5452.htm> Acesso em: 31 mar. 2018.

BRASIL. Decreto n 3.048, de 06 maio 1999. Aprova o Regulamento da Previdência Social e dá outras providências. Diário Oficial da União, Brasília, 7 mai. 1999. Disponível em: <http://www.planalto.gov.br/ccivil_03/decreto/d3048compilado.htm>. Acesso em: 31 mar. 2018.

BRASIL. Lei n ${ }^{\circ}$ 6.938, de 31 ago. 1981. Dispõe sobre a Política Nacional do Meio Ambiente, seus fins e mecanismos de formulação e aplicação, e da outras providências. Diário Oficial da União, Brasília, 2 set. $1981 . \quad$ Disponível em: <http://www.planalto.gov.br/ccivil_03/leis/16938.htm>. Acesso em: 31 mar. 2018.

BRASIL. Lei $\mathrm{n}^{0}$ 12.016, de 7 ago. 2009. Disciplina o mandado de segurança individual e coletivo e dá outras providências. Diário Oficial da União, Brasília, 10 ago. 2009. Disponível em: <http://www.planalto.gov.br/ccivil_03/_ato2007-2010/2009/lei/112016.htm>. Acesso em: 
31 mar. 2018.

BRASIL. Ministério do Trabalho e Emprego. Norma Regulamentadora no 01, de 8 jun. 1978. Disposições gerais. Diário Oficial da União, Brasília, 06 jul. 1978. Disponível em: <http://sislex.previdencia.gov.br/paginas/05/mtb/1.htm>. Acesso em: 31 mar. 2018.

BRASIL. Ministério do Trabalho e Emprego. Norma Regulamentadora nº 04, de 8 jun, 1978. Serviços especializados em engenharia de segurança e em medicina do trabalho. Diário Oficial da União, Brasília, 6 jul. 1978. Disponível em: <http://www.mtps.gov.br/images/Documentos/SST/NR/NR4.pdf>. Acesso em: 31 mar. 2018.

BRASIL. Ministério do Trabalho e Emprego. Norma Regulamentadora n 36, de 18 abr. 2013. Segurança e saúde no trabalho em empresas de abate e processamento de carnes e derivados. Diário Oficial da União, Brasília, 19 abr. 2013. Disponível em: <http://acesso.mte.gov.br/data/files/8A7C812D3DCADFC3013E237DCD6635C2/NR36\%20(atualizada\%202013).pdf>. Acesso em: 31 mar. 2018.

CARVALHO FILHO, José dos Santos. Manual de direito administrativo. São Paulo: Atlas, 2011.

COSTELLA, Marcelo Fabiano; MASSON, Railda. Classificação de tipos de erros humanos: estudo de caso de acidentes em frigoríficos com ocorrências de lapsos de memória. In: XXXII Encontro Nacional de Engenharia de Produção: desenvolvimento sustentável e responsabilidade social: as contribuições da engenharia de produção. Bento Gonçalves, RS, Brasil, 15 a 18 de outubro de 2012. Disponível em: $<$ http://www.abepro.org.br/biblioteca/enegep2012_TN_STO_157_913_19597.pdf>. Acesso em: 31 mar. 2018.

FIORILLO, Celso Antônio Pacheco. Princípios do direito processual ambiental: a defesa judicial do patrimônio genético, do meio ambiente cultural, do meio ambiente digital, do meio ambiente artificial, do meio ambiente do trabalho e do meio ambiente natural no Brasil. 5. ed. São Paulo: Saraiva, 2012.

GAJARDONI, Fernando da Fonseca; FONSECA, Marcelo Furlanetto da. Mandado de segurança coletivo (Lei 12.016/09). Revista Bonijuris, Curitiba, Ano XXIV, nº 578, v. 24, p. 
6-17, jan. 2012. Disponível em: <https://livros-e-revistas.vlex.com.br/vid/mandado-coletivolei-379951578>. Acesso em: 31 mar. 2018.

GOMES, Magno Federici; FERREIRA, Leandro José. A dimensão jurídico-política da sustentabilidade e o direito fundamental à razoável duração do procedimento. Revista do Direito, Santa Cruz do Sul, $\mathrm{n}^{\circ}$ 52, v. 2, p. 93-111, maio/set. 2017. Disponível em: <https://online.unisc.br/seer/index.php/direito/article/view/8864>. Acesso em: 30 mar. 2018.

GRINOVER. Ada Pellegrini. Novas tendências do direito processual: de acordo com a Constituição Federal de 1988. Rio de Janeiro: Editora Forense Universitária, 1990.

LUKACHEWSKI JUNIOR, Wanderlei. Mandado de segurança e a dignidade humana. Cadernos da Escola de Direito e Relações Internacional, Curitiba, v. 1, nº 17, p. 392-414, jan./jun. 2012. Disponível em: $<$ http://revistas.unibrasil.com.br/cadernosdireito/index.php/direito/article/view/818>. Acesso em: 31 mar. 2018.

MEIRELLES, Hely Lopes. Direito administrativo brasileiro. 41. ed. São Paulo: Malheiros, 2015.

MELO, Raimundo Simão de. Direito ambiental do trabalho e a saúde do trabalhador. 3. ed. São Paulo: LTr, 2008.

MENDES, Gilmar Ferreira; BRANCO, Paulo Gustavo Gonet. Curso de direito constitucional. 9. ed. São Paulo: Saraiva, 2014.

MILARÉ, Édis. Direito do ambiente. 9. ed. São Paulo: Revista dos Tribunais, 2014.

NASCIMENTO, Amauri Mascaro. Curso de direito do trabalho. 24. ed. São Paulo: Saraiva, 2009.

ORGANIZAÇÃO INTERNACIONAL DO TRABALHO. Promoção do Trabalho Decente no 
Brasil. OIT, [s/d]. Disponível em: <http://www.ilo.org/brasilia/temas/trabalhodecente/WCMS_302660/lang--pt/index.htm>. Acesso em: 31 mar. 2018.

PACHECO, José da Silva. Mandado de segurança e outras ações constitucionais típicas. 6. ed. São Paulo: Revista dos Tribunais, 2012.

PADILHA, Norma Sueli. Do meio ambiente do trabalho equilibrado. São Paulo: LTr, 2002.

RODRIGUES, Marcelo Prata. O direito ambiental do trabalho numa perspectiva sistêmica: as causas da inefetividade da proteção à ambiência laboral e o que podemos fazer para combatela. São Paulo: LTr, 2013.

SARDA, Sandro Eduardo; RUIZ, Roberto Carlos; KIRTSCHIG, Guilherme. Tutela jurídica da saúde dos empregados de frigoríficos: considerações dos serviços públicos. Acta fisiátrica, São Paulo, v. 16, $\mathrm{n}^{\mathrm{o}}$ 2, p. 59-65, jun. 2009. Disponível em: <http://www.actafisiatrica.org.br/detalhe_artigo.asp?id=109> Acesso em: 31 mar. 2018.

SCHIAVI, Mauro. Manual de direito processual do trabalho. 8. ed. São Paulo: LTr, 2015.

SILVA, José Afonso da. Direito ambiental constitucional. 5. ed. São Paulo: Malheiros, 2004.

THEODORO JUNIOR, Humberto. O mandado de segurança segundo a Lei $\mathbf{n}^{\mathbf{0}} \mathbf{1 2 . 0 1 6}$, de 07 de agosto de 2009. Rio de Janeiro: Forense, 2009.

VASCONCELLOS, Marly de Cerqueira; PIGNATTI, Marta Gislene; PIGNATI, Wanderlei Antonio. Emprego e acidentes de trabalho na indústria frigorífica em áreas de expansão do agronegócio, Mato Grosso, Brasil. Saúde e Sociedade, São Paulo, v. 18, nº 4, p. 662-672, out./dez. $2009 . \quad$ Disponível em: $<$ http://www.scielo.br/scielo.php?script=sci_arttext\&pid=S010412902009000400010\&lng=pt\&nrm=iso > . Acesso em: 31 mar. 2018. 